\title{
Papel semente: uma alternativa para inserção da Educação Ambiental na escola
}

\author{
Seed paper: an alternative for sustainable consumption of paper after school \\ Cadidja Coutinho', Thaís do Canto Dorow' \\ 'Universidade Federal de Santa Maria - RS - Brasil
}

\section{Resumo}

A Educação Ambiental é herdeira direta do debate ecológico e está entre as alternativas que visam construir novas maneiras de os grupos sociais se relacionarem com o meio ambiente. O presente trabalho teve como objetivo demonstrar a importância do reaproveitamento do papel como uma atividade vinculada ao processo de ensino e aprendizagem da Educação Ambiental, proporcionando a transversalidade e buscando desenvolver cidadãos conscientes da sua ação sobre o ambiente natural. A atividade consistiu em uma oficina de reciclagem de papel, realizada com alunos de oitava série do Ensino Fundamental, e produção de papel-semente através do reaproveitamento do material descartado numa escola pública de Santa Maria, RS. Para coleta de dados foi utilizado um questionário e a análise consistiu na aplicação da técnica do Discurso do Sujeito Coletivo. As ideias centrais apresentadas pelos estudantes revelaram suas concepções sobre Educação Ambiental e reciclagem, além da relevância da aplicação do projeto como mecanismo de incentivo à sensibilização ambiental. Dessa forma, a construção de práticas inovadoras não se dá pela reprodução, mas pela criação, pela readaptação e, sobretudo, no caso do papel-semente, por novas relações na organização do trabalho pedagógico.

Palavras-chave: Educação Ambiental, Reciclagem, Discurso do Sujeito Coletivo, Escola, Oficina.

\begin{abstract}
Environmental education is direct heir ecological debate and is among the alternatives that aim to build new ways of social groups relate to the environment. This study aimed to demonstrate the importance of recycling paper as an activity linked to the teaching and learning of Environmental Education, providing the transversal and seeking to develop citizens aware of their actions on the natural environment. The activity consisted of a paper recycling workshop held with students from eighth grade on, and seed production of paper through the reuse of discarded material in a public school in Santa Maria, RS. For data collection a questionnaire was used and the analysis was the application of the technique of the Collective Subject Discourse. The main ideas presented by the students revealed their views on environmental education and recycling, and the relevance of the project application as a mechanism to encourage environmental awareness. Thus, the construction of innovative practices is not given by reproduction but by creation, by upgrading and especially in the case of seed paper for new relationships in the organization of educational work.
\end{abstract}

Keywords: Environmental Education Recycling Collective Subject Speech, School workshop. 


\section{INTRODUÇÃO}

A abordagem das questões ambientais tem mobilizado lideranças e sociedade civil na busca por ações voltadas para o meio ambiente seja através de legislações e de programas governamentais, ou nos diversos empreendimentos de grupos, de associações e de movimentos ecológicos (CARVALHO, 2012; SANTANA et al., 2013).

Segundo Santana et al. (2013) "uma das iniciativas mais marcantes da sociedade foi a institucionalização da Educação Ambiental (EA)", um mecanismo capaz de despertar na população a consciência crítica de suas ações assim como a necessidade de preservação do ambiente natural compartilhado por todos os seres. No processo educativo, a EA tem sido importante intercessora entre a educação e o meio ambiente, debatendo os problemas gerados pela crise ecológica e produzindo mudanças de paradigmas que visam construir as bases de conhecimento e valores ecológicos nesta e nas futuras gerações (CARVALHO, 2012).

Nesse processo, destaca-se a reciclagem de papel na medida em que contribui para a preservação do meio ambiente e para a solução da questão da destinação dos lixos urbanos (BRACELPA, 1998).

Os benefícios da reciclagem do papel incluem, entre outros, a redução no consumo de água e de energia utilizado na produção, muito embora os números sejam bastante divergentes de uma empresa para outra dependendo do tipo de tecnologia empregada e da eficiência do processo. Mas é fato que, com a reciclagem de papel, deixa-se de cortar árvores: calcula-se que para cada 01 tonelada de aparas (papéis cortados usados na reciclagem) deixa-se de cortar de 15 a 20 árvores (BRACELPA, 1998). Além disso, é possível observar que o aumento da conscientização ambiental tem levado a uma maior demanda por papéis reciclados e a pressão para que o papel seja reciclado após sua utilização pelo público (resíduo após o consumo), ao invés de simplesmente jogá-lo nos aterros.

Assim, como afirma Antonie Lavoisier que "(...) na Natureza nada se perde, nada se cria, tudo se transforma (...)", surgiu uma alternativa de reaproveitamento de papel que é modelo de comportamento e ação sustentável - PAPEL SEMENTE ou SEED PAPER. Produzido com pasta base originada da coleta seletiva de papéis recicláveis, sendo processado de forma artesanal, resulta num produto diferenciado dos demais papéis por não ser descartado como lixo após sua utilização, e sim, eliminado de maneira ambientalmente adequada, sendo plantado, gerando árvores, flores, ervas medicinais ou temperos. Os diferenciais do papel-semente estão relacionados ainda às suas características que garantem ser biodegradável e de germinação efetiva.

Com a utilização do papel-semente, além do impacto pela inovação e criatividade, é gerado o diferencial que agrega avançados conceitos de sustentabilidade à produção. Além disso, o uso da técnica pode representar um mecanismo para incentivar o desenvolvimento do sujeito ecológico em crianças e jovens, quando utilizado em espaço escolar.

O problema que norteou essa investigação foi o de como transformar uma prática pedagógica, nesse caso a oficina de produção de papel semente, em uma proposta de inserção transdisciplinar da EA em sala de aula, tornando o educando um leitor crítico das questões ambientais.

Assim, o objetivo deste estudo foi o de demonstrar a importância do reaproveitamento do papel como uma atividade vinculada ao processo de ensino e aprendizagem da EA. Além disso, investigar a concepção dos alunos sobre a EA no contexto da reciclagem do papel e analisar as contribuições da elaboração do papel semente como estratégia de formação da cidadania ambiental.

\section{METODOLOGIA}

A atividade foi realizada com 29 alunos do $9^{\circ}$ ano ( $8^{\mathrm{a}}$ série) do Ensino Fundamental, matriculados no Instituto Estadual de Educação Olavo Bilac, no município de Santa Maria, RS.

A atividade consistiu em uma oficina de reciclagem de papel e produção de papel semente através do reaproveitamento do material pós-consumo na escola. A oficina foi realizada durante o estágio curricular supervisionado das Ciências Biológicas, em turno de aula e com acompanhamento do professor regente de turma.

Antes da realização prática da oficina, foram organizados planos de aula teórica abordando aspectos da história, da composição química e da fabricação do papel, da geração de resíduos, e da Educação Ambiental. O intuito dessas aulas foi orientar, esclarecer e dinamizar os trabalhos posteriores.

O trabalho foi dividido em 3 etapas: (i) Recolhimento de papel descartado nas salas de aula e em outros espaços escolares (Figura 1); (ii) Oficina de reciclagem de papel no laboratório de Ciências da escola (Figuras 2, 3, 4 e 5) ; (iii) Produção de papel semente com utilização de 
sementes pertencentes a plantas de pequeno porte e de germinação rápida, como salsa (Petroselinum crispum (Mill.) Nyman ex A.W. Hill-Apiaceae), rúcula (Eruca vesicaria (L.) Cav.-Brassicaceae) e orégano (Origanum vulgareL.-Lamiaceae) (Figura $6)$.

Em relação aos critérios éticos, os sujeitos da pesquisa assinaram o Termo de Consentimento Livre e Esclarecido, garantindo o sigilo das informações e o seu anonimato, conforme orientações da resolução 196/96 do Conselho Nacional de

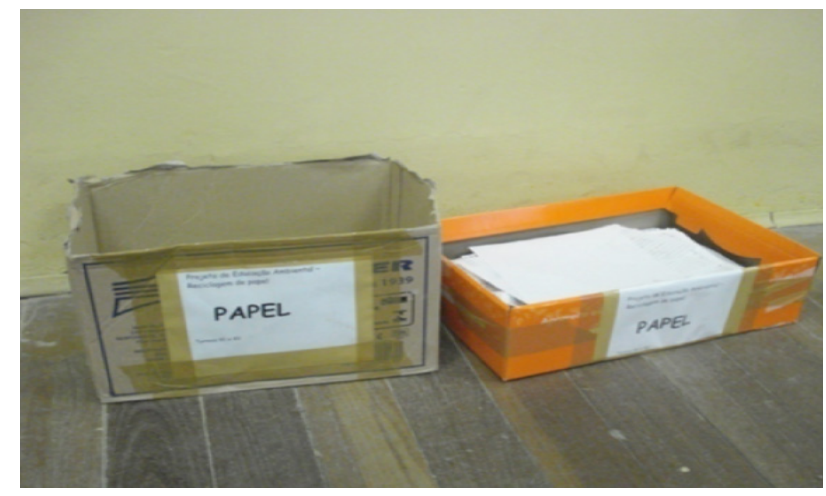

Figura 1. Caixas de coleta de papel descartado.

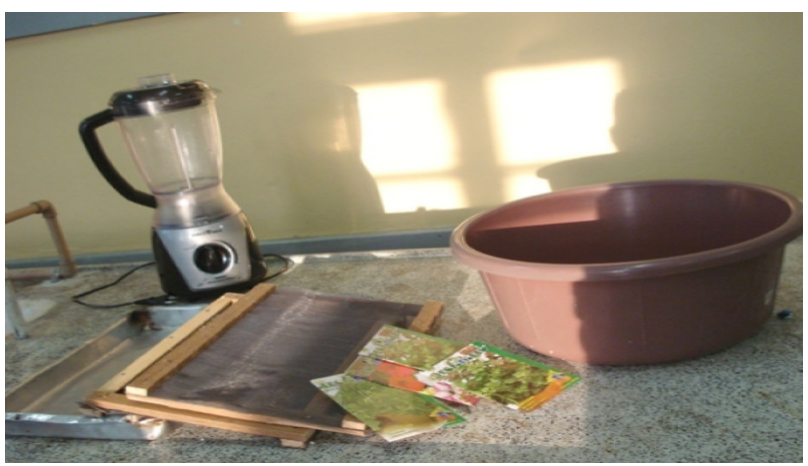

Figura 2. Materiais utilizados para realização da técnica de reciclagem

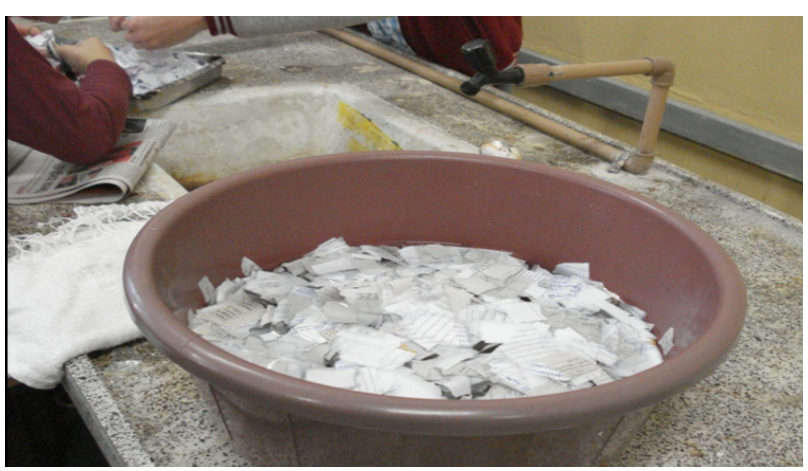

Figura 3. Papel picotado em processo de amolecimento para moagem.
Saúde, do Ministério da Saúde (Brasil, 2006).

Para o desenvolvimento desta pesquisa foi utilizada a abordagem quali-quantitativa. Os métodos quantitativos e qualitativos não se excluem, embora apresentem diferenças quanto à forma $\mathrm{e}$ à ênfase, os métodos qualitativos contribuem para melhor compreensão dos fenômenos (NEVES, 1996). As investigações qualitativas, por sua diversidade e flexibilidade, não apresentam regras rígidas. Segundo Ludke \& André (1986) a pesquisa qualitativa possui o ambiente natural como fonte

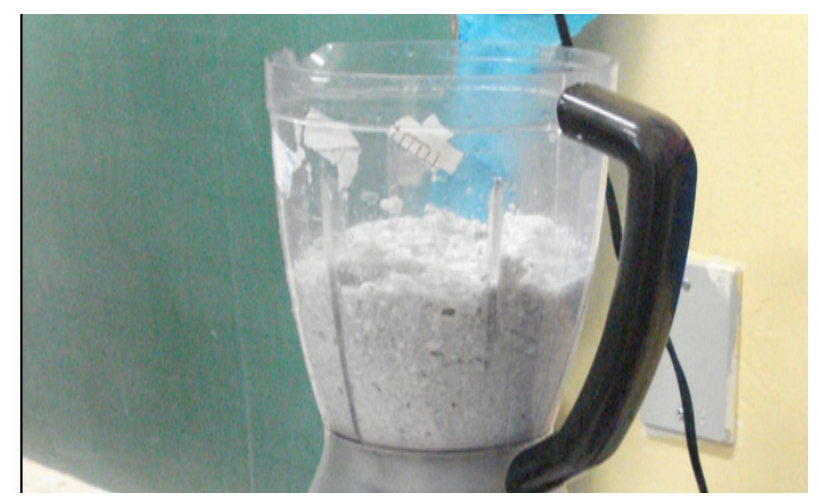

Figura 4. Moagem e formação da polpa de papel.

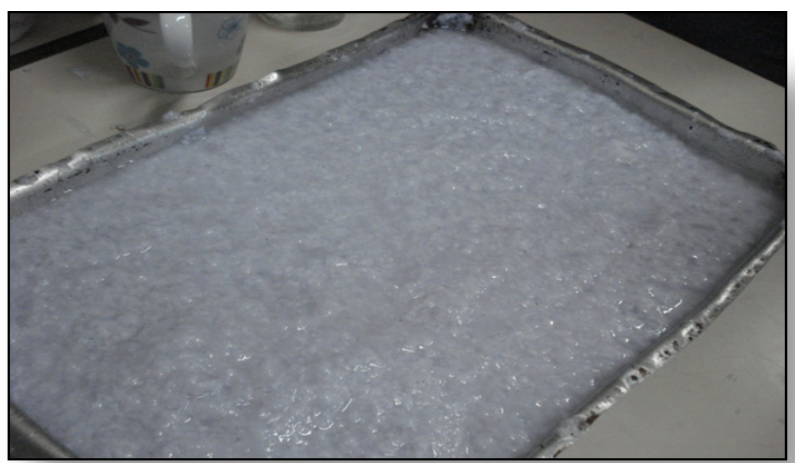

Figura 5. Polpa de papel para filtragem.Figura

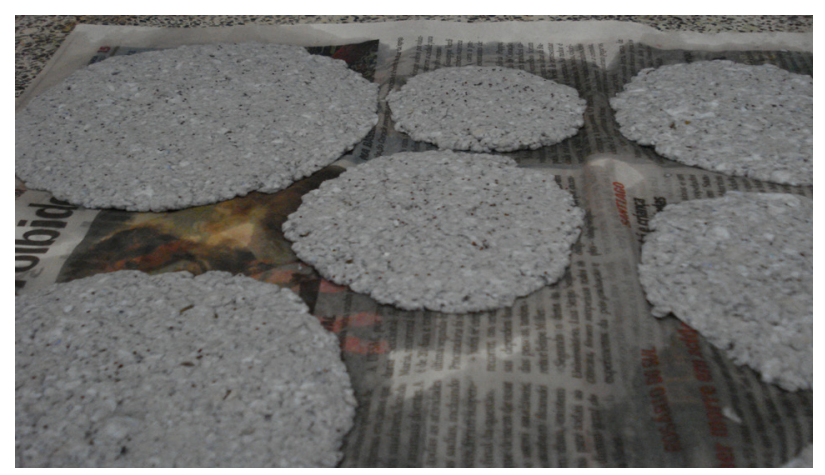

6. Polpa de papel filtrada, impregnada com sementes, constituindo o papel semente. 
direta de dados e o pesquisador como instrumento principal. A pesquisa qualitativa, ainda, supõe o contato direto do pesquisador com o ambiente e a situação que está sendo investigada, via de regra, através do trabalho intensivo de campo. Os dados quantitativos foram organizados em gráficos para melhor visualização.

A coleta de dados foi realizada através de questionário, aplicado durante as aulas de Ciências, um mês após a realização da atividade. O questionário foi elaborado pelas pesquisadoras, baseado em Carvalho (2012); e continha questões abertas referentes ao ensino e à relevância das práticas pedagógicas que envolvem Educação Ambiental. Para análise de dados foi utilizada a técnica denominada Discurso do Sujeito Coletivo (DSC), proposta por Lefèvre e Lefèvre (2003).

A metodologia aqui proposta foi inserida no contexto escolar para promover a interdisciplinaridade com questões ambientais de forma transversal aos conteúdos programados para o ano letivo.

\section{RESULTADOS}

As particularidades da amostra revelam que a turma de oitava série do I. E. E. Olavo Bilac é composta por 29 alunos, sendo 18 do sexo feminino e 11 do sexo masculino, de faixa etária entre 13 a 16 anos de idade.

Todos os alunos da turma participaram da oficina, realizando as etapas necessárias para a confecção do papel semente, a partir da reciclagem do papel descartado nos diferentes espaços da escola.

Quanto ao entendimento de questões relacionadas aos conceitos e a importância da Educação Ambiental, e dos mecanismos de reciclagem de materiais, apresentamos os discursos coletivos dos participantes. Estes discursos estão representados por meio de uma ideia central (IC) e o respectivo número de adeptos. Em alguns casos, um mesmo participante aderiu a mais de uma IC ou não respondeu a questão.

Para a pergunta I:

$O$ que você entende por Educação Ambiental?

IC I.1- Cuidar do meio ambiente (16) aprender a respeitar e preservar os recursos naturais disponíveis ao homem e aos outros seres.

IC I.2- Separação do lixo (10) - fazer o descarte correto dos resíduos.

IC I.3- Conhecer o meio ambiente (8) - entender aspectos referentes aos organismos e às relações existentes no ambiente natural. IC I.4- Reutilizar os diferentes tipos de materiais (4) - reaproveitar os materiais que podem ser submetidos à reciclagem.

DSC I - Educação Ambiental pode ser definida como um meio de preservar o ambiente, principalmente em relação ao descarte correto dos resíduos.

Para a pergunta II: Como você imagina que Educação Ambiental poderia contribuir para amenizar os problemas ambientais? IC II.1- Pela conscientização (17) - amenizar os problemas ambientais esclarecendo e responsabilizando a população.

IC II.2- Incentivo à reutilização de materiais (10) - estimular os processos de reciclagem, reaproveitamento de itens evitando o desperdício.

DSC II - A conscientização da população em relação as suas ações no meio ambiente poderia contribuir para amenizar os problemas ambientais via Educação Ambiental. Para a pergunta III: O que você entende por reciclagem?

IC III.1- Reutilizar (26) - fazer o (re)aproveitamento de materiais para exercer outras finalidades.

IC III.2- Evitar o desperdício (5) - fazer a separação correta e buscar formas para diminuir a quantidade de lixo produzido. DSC III - O termo reciclagem compreende o reaproveitamento de materiais descartados para exercer outras finalidades.

Para a pergunta IV: Qual importância que você atribui para a reciclagem?

IC IV.1- Diminuir a poluição (20) - mecanismo que possibilita a redução da quantidade de lixo, evitando a contaminação do ambiente durante o processo de decomposição.

DSC IV - A relevância da reciclagem está na possibilidade de redução da quantidade de lixo produzido pela população.

Para a pergunta V: O que você faria para ajudar a equilibrar o ambiente em que você vive?

IC V.1 - Não poluir (16) - descartar de maneira correta o lixo.

IC V.2- Evitar o desperdício (12) - fazer o aproveitamento consciente dos recursos naturais.

DSC V - Uma forma de auxiliar o meio ambiente é evitar a poluição e o desperdício 
dos recursos naturais.

Para a pergunta VI: Qual a relação entre o projeto papel semente e a educação ambiental?

IC VI.1- A reciclagem do papel (16) - a conscientização para a diminuição dos resíduos através do reaproveitamento de papel descartado.

IC VI.2- A melhoria do ambiente (14) tentativa de despertar o entendimento das ações humanos e a importância para a conservação do meio ambiente.

DSC VI - O projeto papel semente representa uma alternativa para o reaproveitamento do papel e um incentivo para conscientização ambiental.

Para a pergunta VII: Que outras ações poderiam ser realizadas pela escola para estimular a conscientização ambiental?

IC VII.1- Separação de lixo (14) - distribuir lixeiras de coleta seletiva e oferecer treinamento para sua utilização.

IC VII.2- Movimentos de conscientização (10) - oferecer gincanas, palestras, jogos, visitas para esclarecer e orientar sobre a importância dos recursos naturais e os riscos do uso indiscriminado.

IC VII.3- Mutirão de limpeza (6) - realizar atividades de organização e limpeza do espaço escolar e ambientes próximos.

DSC VII - A instituição escolar deveria realizar atividades vinculadas ao esclarecimento da ação humana sobre os recursos naturais e incentivar a correta separação de lixo.

O Discurso do Sujeito Coletivo (DSC) do estudo advém do conjunto de respostas cedidas pela amostra de alunos entrevistados. Segundo os educandos, a Educação Ambiental incentiva o cuidado com o meio ambiente e a reciclagem pode se tornar um mecanismo para evitar o desperdício e a geração de resíduos. A principal forma de amenizar os problemas ambientais é diminuir a poluição e o projeto papel semente, fazendo uso da reciclagem do papel, pode motivar e despertar a conscientização ambiental, assim como outras iniciativas que deveriam ser propostas pela escola.

\section{DISCUSSÃO}

A análise dos resultados, que emergiu da leitura dos questionários aplicados aos estudantes, apresentada através de discursos coletivos dos participantes sobre conceitos e a importância da $\mathrm{EA}$, e dos mecanismos de reciclagem de materiais, mostrou as ideias centrais dos assuntos.

Quanto ao conceito de EA, a maioria dos entrevistados caracterizou como estratégias, principalmente na separação e reutilização do lixo, para conhecer e despertar a necessidade de preservação do meio ambiente. Esse conceito está de acordo com Carvalho (2012, p. 151), que define Educação Ambiental como "uma proposta ética de longo alcance que pretende reposicionar o ser humano no mundo, convocando-o a reconhecer a alteridade da natureza e a integridade e o direito à existência não utilitária do ambiente".

Entende-se a Educação Ambiental como uma possibilidade de construir uma sociedade mais sustentável e justa democrática e participativa, capaz de estabelecer uma rede solidária de relações não só com esta mais com as futuras gerações. Acredita-se que a educação ambiental é verdadeiramente transformadora se nos levar a construir valores e atitudes intimamente associadas a experiências cotidianas que por sua vez são dimensões da realidade com passado e futuro. Neste sentido, a EA é chave em qualquer caso para renovar os valores e a percepção do problema desenvolvendo uma consciência e um compromisso que possibilitem a mudanças desde pequenas atitudes e participação e envolvimento com as resoluções dos problemas (DIAS, 2004, p.44).

Quando entrevistados sobre a definição e a relevância da reciclagem, a maioria das respostas incluiu a reutilização de materiais descartados, de forma a reduzir o desperdício e a poluição ambiental. Informação esta, corroborada por Guadagnin (2010 apud ASSAD et al., 2011, p. 54) que afirma que "ao minimizar a produção dos resíduos comuns por meio da segregação daqueles passíveis de reciclagem, há a redução da quantidade disposta desses resíduos no meio ambiente".

A temática de reciclagem de materiais é abordada em diferentes contextos na pesquisa em EA (por exemplo, BASTIANELLO, 2005; ASSAD et al., 2011), mostrando ser um mecanismo para inserção de conceitos (como padrões de consumo, volume do lixo, desperdício, disposição no ambiente e coleta seletiva), do espírito crítico em relação à exploração dos recursos naturais, e principalmente a formação de uma cidadania 
ambiental.

Ao questionar as ações que poderiam ser realizadas pelos estudantes, visando à melhoria da problemática ambiental, uma parcela significativa aponta as questões referentes ao lixo e ao desperdício, tema também retratado em outras questões. Apesar de ser um assunto de relevância social e tema de investigação de pesquisas na área (SANTA MARIA et al., 2003; MENEZES et al., 2005; CAMPOS \& CASSAVAN, 2007; SANTOS et al., 2011), o lixo não é o único aspecto relevante quando se fala em EA.

Essa concepção pode estar associada ao descaso em relação às atividades didáticas que envolvam o ideário ecológico transversalmente ao conteúdo programático do ano letivo. Dessa forma, as falas dos alunos podem ser reflexo da inserção do assunto durante as atividades propostas pela oficina aqui descrita e pouco citada anteriormente ao projeto. Assim:

O processo educativo deve ser planejado e vivenciado no sentido de possibilitar, aos indivíduos, uma compreensão, sensibilização e ação que resulte na formação de uma consciência da intervenção humana sobre o ambiente, que seja ecologicamente equilibrada. Para isso, espera-se que o mesmo seja conduzido no sentido de possibilitar a formação de um pensamento crítico, criativo e conectado com a necessidade de propor respostas para o futuro, capaz de analisar as complexas relações entre os processos naturais e sociais e de atuar no ambiente em uma perspectiva global, respeitando as diversidades socioculturais (NETO \& AMARAL, 2011, p. 130).

A temática ambiental está descrita na Constituição Federal de 1988; em seu artigo 225 "promover a educação ambiental em todos os níveis de ensino e a conscientização pública para a preservação do meio ambiente"; na Lei Federal 9795/99, que instituiu a Política Nacional de Educação Ambiental, a qual incumbe às instituições educativas "promover a educação ambiental de maneira integrada aos programas educacionais que desenvolvem" (BRASIL, 1999) e é também indicada pelos PCN (BRASIL, 1997, 1999) como integrante do processo educacional.

Os PCN sugerem que a abordagem ambiental esteja relacionada às diferentes áreas do saber, integrado as disciplinas do currículo escolar e trabalhado interdisciplinarmente para provocar as mudanças, visando enfocar aspectos das modificações ambientais causadas pelas ações antrópicas ou naturais, além do uso e implicações ambientais, sociais e econômicas decorrentes dos processos de produção (LATINI \& SOUSA, 2011).

Em relação à visão dos alunos sobre o projeto papel semente, as ideias centrais mostram que a atividade teve como cunho desenvolver a criticidade em relação ao papel descartado diariamente na escola, despertar questionamentos sobre a relação homem-natureza e motivar o cuidado com o meio ambiente.

O papel é um lixo nobre, pois sua reciclagem preserva o meio ambiente evitando o corte de milhões de árvores que através da fotossíntese ainda absorve o gás carbônico da atmosfera e na liberação do oxigênio para a mesma isso torna o ar que respiramos com melhor qualidade. Deve-se levar em conta também o papel que o gás carbônico tem no aquecimento global. A reciclagem de papel não apenas preserva as árvores, que são cortadas para fabricá-la, mas também reduz a poluição do ar e da água e conserva valiosa energia (BARBOSA JUNIOR, 2006, p.23).

A EA tem como um de seus objetivos construir um novo ideário ambiental que nos possibilite uma visão mais ampla sobre a relação do homem com a natureza (NEIMAN \& RABINOVICI, 2002; NETO \& AMARAL, 2011). Nesse processo de mudança de concepções, as ações educativas tem papel fundamental na formação de um ambiente de aprendizagem social e individual capaz de promover a formação do sujeito humano, com novos pensamentos, atitudes e sensibilidades ambientais (CARVALHO, 2012).

Neto \& Amaral (2011) analisaram estratégias didáticas utilizadas por professoras de Ciências para o desenvolvimento de temas ambientais nas turmas de Ensino Fundamental II, e avaliariam se e/ou como tais estratégias contribuem para a implantação de uma proposta de EA Crítica nesse nível de ensino. Os dados mostraram que estratégias didáticas podem constituir elementos fundamentais para o desenvolvimento da EA Crítica, quando contribuem para que o processo educativo não se resuma ao uso do livro; valorizam o diálogo entre saberes em uma dinâmica interativa, e, ainda, a necessidade da inclusão dos princípios norteadores da EA Crítica na formação continuada de professores. 
Gonçalves e Sá e colaboradores (2012), a partir de dados obtidos na pesquisa "Relação entre a teoria e a prática da Educação Ambiental na EJA do SESC - Petrolina/PE", afirmam ser fundamental a inclusão de projetos ecopedagógicos no ensino formal, permeando de maneira transversal as disciplinas ofertadas pelo currículo, relacionando a interdisciplinaridade de modo a formar cidadãos conscientemente críticos do seu papel na sociedade.

Em relação às ações que poderia ser propostas pela escola, as ideias centrais dos alunos retratam exemplos de atividades de fácil organização e com objetivos voltados à EA. Fracalanza (2004, p.7) defende que a EA nas escolas deve se aproximar de uma "atividade contínua; com caráter interdisciplinar; com um perfil pluridimensional; voltada para a participação social e para a solução de problemas ambientais; visando a mudança de valores, atitudes e comportamentos sociais".

Em São Paulo, após a percepção sobre o que seria o seu meio ambiente e a importância de modificar sua realidade, crianças envolvidas em atividades de educação ambiental propuseram interferências como mutirões de limpeza, instalação de lixeiras e mobilizações para conscientização de moradores (REIGADA \& REIS, 2004), interferindo na realidade local e propiciando uma discussão crítica da realidade local para toda a comunidade (AGUILAR et al., 2013).

A educação se transforma quando usa metodologias que levam o aluno a participar e a criar novas oportunidades de ensino e aprendizagem. A temática ambiental precisa ser abordada nas escolas com mais dinamismo, de forma marcante e lúdica, capaz de mobilizar os alunos e a comunidade local da responsabilidade ambiental de todos. É necessário que o discente problematize e entenda as consequências de suas ações ao ambiente natural. Desta forma, as mobilizações da comunidade escolar para a mudança de hábitos e atitudes pode tornar o espaço escolar um ambiente crítico e que contribua para a formação de cidadãos conscientes e atuantes na busca por soluções à problemática ambiental.

\section{CONCLUSÃO}

Este estudo propôs uma prática pedagógica como alternativa para inserção da EA em sala de aula de forma transdisciplinar e dinâmica. Os alunos consideraram a oficina de reciclagem de papel e produção de papel semente como uma forma de sensibilização e conscientização para a formação da cidadania ambiental.

O comportamento e os discursos dos participantes da atividade mostraram a importância do reaproveitamento do papel como uma atividade vinculada ao ensino e aprendizagem da EA. A criticidade dos alunos diante de situações de desperdícios que ocorreram após as atividades aqui propostas, como na distribuição de folders e/ou bilhetes informativos, demonstrou estarem preocupados com as questões ambientais.

Do mesmo modo, os princípios propostos pela atividade refletiram a mudança de paradigmas de outros membros da escola. As auxiliares de serviços gerais, quando solicitado e destacado a importância de manter o papel a ser reciclado nas caixas de coleta; a direção e as coordenações no acompanhamento, disponibilização de materiais e do espaço escolar; e o corpo docente que visualizou na atividade uma estratégia pedagógica de fácil execução em diferentes contextos de ensino.

A compreensão dos alunos, pelo menos em parte, sobre o significado da degradação sócio ambiental, se tornou fundamental para desenvolver valores e atitudes que estimulassem a formação do sujeito ecológico em cada um. Além disso, a EA foi vista como um mecanismo de intervenção de caráter educativo e transformador, vinculado a estratégias que permitem o desenvolvimento de uma prática social de construção e sistematização de conhecimentos que levam a atuação consciente sobre o meio ambiente.

Entretanto, é importante refletir que a EA representa uma alternativa para transformar a realidade, mas não deve ser vista como única e responsável por todas as mudanças. Precisamos de comprometimento individual e coletivo com o ambiente.

\section{REFERÊNCIAS}

AGUILAR, T. M., REIS, J. E., CASTILHO, V. M., RIBEIRO, F., \& LINS, L. V. Oficinas de educação ambiental do Projeto pato aqui, água acolá em Escolas de São Roque de Minas, MG. e-Scientia, v.6, n.1, 2013.

ASSAD, L. G., BERARDINELLI, L. M. M., DA SILVA, D. P. P., DE OLIVEIRA JUNIOR, A. A. B., \& RODRIGUES, T. G. Reciclagem de papel: uma experiência de ensino, extensão e pesquisa. Interagir: pensando a extensão, n.16, p. 53-57, 2011. 
ASSOCIAÇÃO BRASILEIRA DE CELULOSE E PAPEL - BRACELPA. Considerações gerais sobre a atividade de reciclagem de papel no Brasil. São Paulo, BRACELPA. Palestra, III Seminário de Avaliação de Experiências Brasileiras de Coleta Seletiva de Lixo, 1998.

BARBOSA JÚNIOR, J. S. Reciclagem de papel? Iv. 35p, il. Gráfs. Fots, 2006.

BASTIANELLO, S. F. Desenvolvimento de embalagens a partir de papel reciclado reforçado com fibras naturais: uma proposta ambientalmente amigável. Dissertação de mestrado apresentada ao Programa de Mestrado em Saúde e Meio Ambiente. Universidade da Região de Joinville, 2005.

BRASIL, Secretaria de Educação Fundamental, Parâmetros Curriculares Nacionais: meio ambiente, saúde. Brasília: Secretaria de Educação Fundamental, 1997.

BRASIL. Ministério da Educação do Brasil. Parâmetros Curriculares Nacionais: Ensino Médio. Brasília: Secretaria de Educação Média e Tecnológica, 1999.

BRASIL. Ministério da Educação, Secretaria de Educação Básica. Orientações curriculares para o ensino médio- Ciências da natureza, matemática e suas tecnologias. Brasilia: MEC/Semtec, 2006.

CAMPOS, S.S.P.; CAVASSAN, O. A oficina de materiais recicláveis no ensino de ciências e nos programas de educação ambiental: refletindo sobre a prática educativa. Anais do VI Encontro Nacional de Pesquisa em Educação em Ciências (ENPEC). Disponível em: http://www.fae.ufmg.br/abrapec/viempec/viempec/entrar.html. Acesso em 10 out 2013.

CARVALHO, I. C. M. Educação ambiental: a formação do sujeito ecológico / Isabel Cristina de Moura Carvalho - 6. ed. - São Paulo: Cortez, 2012.

DIAS, G. F. Educação Ambiental: princípios e praticas. $9^{\circ}$ Ed. São Paulo: Gaia; 2004.

FRACALANZA, H. As pesquisas sobre educação ambiental no Brasil e as escolas: alguns comentários preliminares. In: TAGLIEBER, J. E.; GUERRA, A. F. S. (Orgs.) Pesquisa em educação ambiental: pensamentos e reflexões; I Colóquio de Pesquisadores em Educação Ambiental. Pelotas: Ed. Universitária, UFPel, 2004.
GONÇALVES e SÁ, Á. K., PEREIRA, C. D. A., \& MOURA, R. C. G. Relação entre a teoria e a prática da educação ambiental na EJA do SESC-Petrolina/ PE. Revista de Educação, Ciências e Matemática, v. 2, n.1, 2012.

GUADAGNIN, M.R. Gerenciamento de Resíduos de Saúde: É possível minimizar? Disponível em: <www.unesc.net/noticias/index.php?ver=arquivo>. Acesso em: 17 out. 2010.

LATINI, R. M.; SOUSA, A. C. Ensino de química e ambiente: as articulações presentes na Revista Química Nova na escola (QNEsc). Investigações em Ensino de Ciências, v.16, n.1, p. 143-159, 2011.

LEFÈVRE, F.; LEFÈVRE, A. M. C. O discurso do sujeito coletivo: um novo enfoque em pesquisa qualitativa (desdobramentos). Caxias do Sul: EDUSC, 2003.

LUDKE, M.; ANDRÉ, M.E.D. A Pesquisa em educação: abordagens qualitativas. São Paulo: E.P.U. 1986.

MENEZES, M.G., BARBOSA, R.M.N, JÓFILI, Z.M.S.; MENEZES, A.P.A.B. Lixo, cidadania e ensino: entrelaçando caminhos. Química Nova na Escola. 2005. Disponível em: http://qnesc.sbq.org. br/online/qnesc22/a08.pdf. Acesso em: 10 out. 2013.

NEIMAN, Z; RABINOVICI. O cerrado como instrumento para educação ambiental em atividades de ecoturismo. In: NEIMAN, Zysman (Org). Meio ambiente, educação ambiental e ecoturismo. São Paulo: Manole, 2002.

NETO, A.L.G.C; AMARAL, E.M.R. Ensino de ciências e educação ambiental no nível fundamental: análise de algumas estratégias didáticas. Ciência \& Educação (Bauru) v.17, n.1, 2011.

NEVES, J.L. Pesquisa Qualitativa: características, usos e possibilidades. Caderno de Pesquisa em Administração, São Paulo, v.1, n.3, 1996.

REIGADA, C., \& REIS, M. F. C. T. Educação ambiental para crianças no ambiente urbano: uma proposta de pesquisa-ação. Ciência \& Educação, v. 10, n. 2, p.149-159, 2004.

SANTA MARIA, L.C.; LEITE, M.C.A.M.; AGUIAR, M.R.M.P.; OLIVEIRA, R.O.; 
ARCANJO, M.E.; CARVALHO, E.L. Coleta seletiva e separação de plásticos. Química Nova na Escola. 2003. Disponível em: http://qnesc.sbq.org.br/ online/qnesc17/a08.pdf. Acesso em: 10 out. 2013.

SANTOS, P. T. A., DIAS, J., LIMA, V. E., OLIVEIRA, M. J., NETO, L. J. A., \& CELESTINO, V. Q. Lixo e reciclagem como tema motivador no Ensino de Química. Eclética Química, v. 36, n. 1, p. 78-92, 2011. 